\title{
Variations
}

Variations

Revue internationale de théorie critique

$23 \mid 2020$

Pour une gauche érotique

\section{Le folklore Quechua comme vecteur de l'émancipation indigène}

Entretien avec Jacques Guyot et Danièle Téphany

Leo Casas Ballón

\section{OpenEdition}

Journals

Édition électronique

URL : http://journals.openedition.org/variations/1367

DOI : $10.4000 /$ variations. 1367

ISSN : 1968-3960

Éditeur

Les amis de Variations

Référence électronique

Leo Casas Ballón, «Le folklore Quechua comme vecteur de l'émancipation indigène », Variations [En

ligne], 23 | 2020, mis en ligne le 01 septembre 2020, consulté le 07 septembre 2020. URL : http://

journals.openedition.org/variations/1367 ; DOI : https://doi.org/10.4000/variations.1367

Ce document a été généré automatiquement le 7 septembre 2020

Les ami•e•s de Variations 


\section{Le folklore Quechua comme vecteur de l'émancipation indigène}

Entretien avec Jacques Guyot et Danièle Téphany

Leo Casas Ballón

$\mathrm{Si}$, dans le monde, certaines langues et cultures arrivent encore à se maintenir face à l'hégémonie de langues officialisées par les États-Nations ou les réseaux numériques mondialisés, c'est moins grâce à la promotion de la diversité culturelle, souvent réduite à un faire-valoir touristique ou patrimonial par de nombreux pays ou organisations internationales, qu'à l'opiniâtreté de personnes appartenant à des communautés minorisées qui font de la défense de leurs idiosyncrasies un outil de résistance et d'émancipation. On sait depuis Richard Hoggart ce que la culture populaire renferme comme potentiel subversif, notamment quand il s'agit de résister et de s'affirmer contre l'ordre culturel établi. C'est ce que fait Leo Casas Ballón, poète, musicien et écrivain quechua né à Cusco en 1942 qui a fait de sa vie un combat où le chant, la danse, les récits, les rituels traditionnels de la culture quechua constituent la matière-même de la résistance à l'oppression. Nous l'avons rencontré à plusieurs reprises, au Pérou (en 2012 et 2014) dans le cadre de nos recherches et, en France, en 2016, à l'occasion d'une invitation pour un colloque sur les langues et peuples minorisés. Leo Casas habite un pays qui est une véritable mosaïque de parlers, avec 17 familles linguistiques dont celle des langues amazoniennes, lesquelles comptent quelques 40 idiomes. L'émiettement prédomine largement avec une majorité de langues pratiquées par seulement une centaine de locuteurs. Dans cette gamme de langues indigènes, c'est le quechua qui est le plus parlé, après le castillan, par 4,7 millions d'individus, sur une population péruvienne totale de 28 millions d'habitants. Pour autant, la survie du quechua n'est pas garantie comme le rappelle Leo Casas dans ces échanges.

1 Jacques Guyot \& Danièle Téphany - Peux-tu te présenter et situer ton parcours ?

2 Leo Casas Ballón - Je suis né dans la ville de Cusco et ma langue maternelle est le quechua ; c'est la langue de mes parents et celle dans laquelle j'ai été éduqué et formé. Mes parents venaient de la région de l'Apurimac où vivaient des populations qui historiquement n'ont pas accepté la domination inca. Ils ont organisé une fédération 
avec d'autres peuples qui entendaient maintenir leur liberté et leur autonomie face aux Incas. Alors, ils ont fait la guerre. Bref, je suis de Cusco par ma naissance, mais d'Apurimac par mes parents et d'Ayacucho d'adoption. Je parle, lis, écris et traduis le quechua. Je connais la langue et la culture andine dans ses manifestations les plus diverses qui viennent de la connaissance et de la relation avec la nature, avec un lien très fort entre l'homme et la nature qui est présent dans tous les actes de la vie humaine, dans la musique, le chant qui est aussi ma spécialité, la littérature quechua, les récits, les contes, les mythes, les légendes, la poésie. Tout est imprégné de cette philosophie de l'homme indissociable de la nature et qui, à partir de là, développe toute une pratique de vie autour d'une relation harmonieuse et respectueuse de la nature, mais aussi avec les êtres humains, les animaux, les plantes, les rivières, les lacs, etc. C'est une cohabitation fraternelle, parce que tous sont interdépendants comme fils de la terre mère. C'est ce que j'ai fait pendant toute ma vie : approfondir ces connaissances, les utiliser systématiquement dans la formation de leaders et de jeunes, participer aux efforts d'organisation des communautés pour améliorer la santé, l'alimentation, la médecine et, bien sûr, la partie économique.

\section{JG-DT - C'est la culture que t'ont transmise tes parents ?}

4 LCB - Oui, il y a une chose étrange dans mon cas. Tu vois mon visage, j'ai des traits européens. Mais ma mère était locutrice quechua et maîtrisait très mal le castillan. Elle était analphabète. Elle a appris à écrire son nom à l'âge de 64 ans. Elle était accoucheuse, guérisseuse et catéchiste, et donc un peu leader spirituelle de la communauté. J'ai des centaines de frères et sœurs dans de nombreuses communautés qui sont nés des mains de ma mère, dans les provinces de Cusco et d'Apurimac. Ma mère cohabitait avec la famille du nouveau-né pendant 15 jours et préparait tous les jours le bain de la jeune mère et de son enfant avec des herbes aromatiques, ainsi qu'un régime alimentaire spécial. Le soir, elle se réunissait avec les familles de la communauté pour chanter, prier et bénir la venue du nouvel être, resserrant les liens de l'ayllu (la communauté en quechua). J'ai été l'accompagnateur et le secrétaire de ma mère dès l'âge de 6 ans. Ma mère ne savait ni lire, ni écrire, mais comme elle était catéchiste, elle avait des cahiers avec des prières, des chansons et une série de choses religieuses. Elle avait la clé de l'église, faisait sonner les cloches et faisait dire le chapelet. Quant à moi, je restais jouer avec les enfants et leur apprenais les chansons et les prières en quechua. Les femmes, les filles des compagnes de ma mère qui étaient nées de ses mains et étaient ses filleules, non pas suite à un baptême, mais parce qu'elle leur avait couper le cordon ombilical, ont émigré de la communauté.

Je suis né en 1940, justement au moment des plus fortes migrations. Á Lima, le taux le plus élevé de migrants venait de l'Apurimac, d'Ayacucho et de Huancavelica. Aussi, beaucoup des filles des compagnes de ma mère ont vécu à Lima comme domestiques, à condition d'aller aux cours du soir pour apprendre à lire et à écrire. Mon père était plus blanc que moi, il avait les yeux bleus et était métissé turco-arabe, parce qu'il y avait beaucoup de familles turques et arabes à Abancay. Mon père n'était quasiment jamais à la maison, car il travaillait loin : il venait passer une semaine à la maison une fois tous les trois mois et parfois tous les six mois ou même un an. Mon père était un personnage mythique dans la famille. Il parlait toujours en quechua et était bon musicien : il jouait de la quena, de la guitare avec diverses façons de l'accorder, de la bandurria (sorte de mandoline) et du charango. Je l'écoutais attentivement et devais répéter les paroles des chansons dont il m'expliquait le sens. Il ne dansait ni ne chantait, mais ma mère était 
une excellente chanteuse. C'est de là que viennent mes capacités à mémoriser rapidement les chansons. Mais j'étais aussi le traducteur de ma mère, ce qui m'a appris à analyser le texte les chansons, à les traduire à partir de six ans. Nous n'avions pas de terres ou de maison, mais nous avons bien vécu, justement, parce qu'en plus de l'affection des marraines et des filleul.le.s de ma mère, nous recevions de petits cadeaux comme du chocolat, des pommes de terre, du fromage ou du lait. Ses filleules disaient, "Mama, voilà un peu de lait de notre vache " et elles apportaient du lait ; "Mama, nous allons aux champs, nous allons semer du maïs et mes frères vont nous aider ». Nous n'avons jamais manqué de nourriture. Treize enfants, nous étions treize du même père et de la même mère. Nous n'avons jamais eu faim grâce à l'affection constante des gens, bien que nous n'avions pas un mètre carré de terre, ni de maison à nous. Ma mère ne se faisait pas payer pour son travail. C'était donc cette relation plutôt spirituelle dans un cadre social très fort qui nous a donné une certaine sécurité matérielle. Au-delà de tout cela, je m'identifie à ces gens, à leur situation, à leur culture, leur musique et leurs chansons. Mes autres frères ne sont pas comme moi, parce qu'ils n'ont pas eu cette proximité avec ma mère. Ils pensent que je suis fou de préférer travailler dans les communautés, plutôt que dans un ministère ou une université.

JG-DT - Tu as été également influencé par la culture castillane, et notamment par un des grands auteurs ibériques?

7 LCB - Oui, entre 8 et 14 ans, j'ai lu quatre fois le Quichotte de Cervantès, les deux tomes de l'édition espagnole avec de très bonnes illustrations. Je traduisais des chapitres en quechua pour les raconter comme des contes, parce que lorsqu'il pleuvait et que l'on devait trier les feuilles de coca ou écosser les cacahuètes, il fallait raconter des contes. J'adaptais les chapitres en contes à la façon andine. Pour moi, cela a été un enchantement parce que cela me reliait à la littérature universelle, cela m'a ouvert à un monde totalement différent : connaître le castillan et les coutumes de cette époque et, ensuite, mettre tout cela en accord avec l'idéologie des gens qui venaient de Cusco, de l'Apurimac.

\section{JG-DT - Pour revenir à la langue, quelle était la situation dans les écoles quant à} l'usage du quechua?

LCB - Brutalement réprimé. Dans l'école où j'étudiais, les exemples qui me viennent à l'esprit sont ceux d'une grande brutalité, du traitement terrible que nous infligeaient les maîtres. Si un mot de notre langue maternelle nous échappait, nous étions insultés et punis. Parce que j'étais blanc, on m'insultait encore plus, car les blancs ne devaient pas parler quechua mais au contraire enseigner à bien parler et à prononcer le castillan aux autres, à ceux qui n'étaient pas blancs, qui étaient indigènes. À l'école primaire, mon professeur m'a donné le surnom de cara de gente (face de personne), parce que le terme de personne désignait exclusivement les blancs. Mais si j'avais le visage d'un blanc, à l'intérieur, j'étais quechua. Quand je chantais dans les fêtes, les carnavals, on me disait souvent : " avec le visage que tu as, tu ne devrais pas chanter comme un petit indien de la Puna ». À l'école, tu venais pour perdre ton identité d'indien et moi, avec ma face de personne, j'étais plus indien que les autres. En fait, le surnom que l'on me donnait était une façon de m'insulter, de rabattre ma fierté.

Actuellement, il y a peu d'écoles interculturelles bilingues; elles sont généralement privées et dirigées par des institutions religieuses qui utilisent l'enseignement interculturel bilingue non pas pour développer la culture indigène auprès des enfants, mais pour inoculer les valeurs de l'église catholique, de l'église protestante. Bon, ils ont 
de bonnes intentions, mais ils ont une mentalité étrangère, eurocentriste. Ils importent le discours européen ou nord-américain sur le féminisme là où, depuis 8000 ans, la femme est l'égale de l'homme dans la culture quechua. Avec la meilleure intention du monde, se produit un choc culturel avec un point de vue extérieur, superficiel, peu curieux des réalités locales, tant de la part des révolutionnaires de gauche que des acteurs institutionnels ou non-gouvernementaux du changement social. Qui plus est, le quechua ne bénéficie pas toujours de l'appui des populations indigènes : des familles s'opposent à l'enseignement interculturel bilingue pour leurs enfants dans leur propre communauté. Si leurs enfants apprennent le quechua, jamais ils n'apprendront le castillan, l'enseignement interculturel bilingue est considéré comme un plan pervers du gouvernement pour que les indigènes n'aillent jamais en ville pour conquérir un autre niveau de vie. Je rencontre, dans beaucoup de communautés indigènes, des parents qui sont contre l'enseignement interculturel bilingue, parce que c'est un projet pervers visant à empêcher leurs enfants d'apprendre le castillan pour trouver du travail en ville et avoir une vie meilleure.

11 Il y a près de 4 millions de locuteurs quechua au Pérou, mais la langue diffère d'une région à l'autre; la langue écrite est certes normalisée, mais si on prend le cas de Lima où il $\mathrm{y}$ a beaucoup d'immigrés, plus de $70 \%$ n'ont pas reçu d'enseignement pour lire et écrire le quechua. Aussi, les gens sont toujours incapables de lire leur propre langue maternelle. En fait, nous sommes peu à maîtriser la lecture de notre langue avec l'alphabet normalisé. Cela ne s'enseigne pas, comme par exemple avec le $q[\mathrm{x}]$ ou le $h$ aspiré, deux sons qui n'existent pas en castillan. Beaucoup de gens chantent en quechua, mais n'ont pas accès à la traduction de la richesse expressive de leur langue. C'est un grand désavantage pour nous et une partie de notre lutte porte là-dessus, sur la diffusion de l'écriture par le biais des chansons. C'est ce qui nous relient les uns aux autres, ce qui nous amalgame aux divers secteurs sociaux pratiquant des variantes dialectales du quechua : la chanson est notre culture commune. L'autre source, ce sont les contes, les mythes et les légendes qu'il faut également écrire et enregistrer pour que les gens sachent comment prononcer et écrire. C'est la tâche que nous menons.

JG-DT - Y-a-t-il un soutien de la part des instances officielles péruviennes ?

13 LCB - Oui, et ce grâce au Ministère de la culture et au Ministère de l'éducation qui a notamment un service dédié à l'éducation interculturelle bilingue. Une loi votée en 2001 organise l'enseignement obligatoire du Quechua et de l'Aymara dans les écoles primaires et secondaires et dans l'enseignement supérieur. Ils produisent notamment du matériel pédagogique pour les écoles, pas seulement en quechua. Ils travaillent aussi à la normalisation linguistique : il existe environ une trentaine de variations dialectales du quechua au Pérou, dont six sont parlées par la majorité de la population andine. Le problème est la formation des professeurs, en nombre insuffisant. Et aussi que les parents ne sont pas d'accord comme je le disais précédemment.

JG-DT - Peux-tu nous parler de ta vision du folklore andin, du rôle que tu lui assignes dans la vie quotidienne des communautés quechua? Le folklore couvre beaucoup de choses : la musique, les chansons, les danses, les traditions, les rituels, les énigmes, etc. Mais dans le cas présent, je vais davantage m'intéresser au chant comme facteur important d'union, de cohésion sociale, d'amalgame de divers secteurs sociaux qui étaient auparavant antagonistes. Dans la culture andine, tout se fait en chantant, de la naissance à la mort, chaque moment de la vie quotidienne a sa propre chanson; chaque activité comme les semailles ou la récolte 
possède également sa chanson, ou encore les départs ou les retours d'exil. Voilà, ce sont toutes ces chansons que j'ai apprises avec ma mère, dès mon plus jeune âge : comme toutes les femmes quechuas, elle avait un grand châle coloré qui lui servait à porter son bébé sur son dos et lui permettait de travailler, mais aussi de danser et de chanter. J'ai appris le rythme, la musique et les paroles de mes premières chansons de cette façon. Pour moi, ce n'est pas une théorie, une invention ou une hypothèse gratuite, mais quelque chose de normal de dire que chanter, c'est la première forme de protestation et de dénonciation face à l'oppression, à la marginalisation. Je crois que l'identité est renforcée et unie avec le chant, le conte, la musique, la danse dans une société qui a des milliers d'années d'oralité, de traditions orales. C'est donc une façon de transmettre bien plus que du divertissement: le chant, la musique, la danse et les rituels sont des langages symboliques pour transmettre des valeurs et des savoirs. Ceci est important pour construire une société meilleure, c'est-à-dire démocratique, égalitaire, fraternelle, juste et bien sûr pacifique.

16 José Maria Arguedas est un écrivain et ethnologue péruvien qui a beaucoup écrit sur la réalité indigène, sur le folklore et la culture orale quechua (en quechua et en espagnol) ; il remarquait qu'à Lima, mais aussi à Puno, il était malvenu pour un paysan quechua de se promener dans les rues dans son costume traditionnel et, a fortiori, de danser et de chanter, notamment lors de fêtes, dans la rue qui symboliquement est le lieu public de l'oppression. Aussi, pour nous, chanter est une forme de résistance, une forme de lutte, mais également un moyen de communication, d'être en harmonie avec les autres. Et cela, l'état avec ses institutions veut l'étouffer. En chantant, on fait chanter les gens et on les ouvre au débat, comme on le fait dans nos assemblées communautaires. Et cela a toujours été considéré comme subversif : chanter, c'est un acte de révolte, c'est un acte de subversion parce qu'on continue à être un peuple réduit au silence, avec une culture et une langue réprimées. S'ils pouvaient faire disparaître le quechua, ils le feraient. À tel point que, récemment, pour la première fois dans l'histoire du Pérou, la télévision nationale d'État a annoncé qu'elle allait transmettre de cinq à six heures du matin, du lundi au vendredi, un journal d'informations en quechua. Pas pour faire parler comme on le fait dans une discussion avec les gens, quand ceux-ci disent ce qu'ils veulent dire, font des déclarations, posent des questions et échangent, mais pour relater ce que font les ministres, les députés. Pour une population de près de 4 millions, dont 1 million vivant dans la capitale, une télévision qui dispose de 1000 antennes relais dans le pays va lancer un programme non pour faire parler les paysans, mais pour parler aux indigènes de ce que fait le milieu politique officiel. Tout ceci est présenté comme un grand pas en avant.

17 JG-DT - Tu as beaucoup travaillé dans et pour les radios communautaires indigènes. Peux-tu parler du rôle de la radio comme élément majeur de la transmission de la langue et de la culture quechua ?

18 LCB - J'ai évoqué le fait que notre société est de tradition orale. Là, la radio multiplie cet effet magique de la voix et du son que produisent les pierres qui ont une âme. Les collines ont une âme, ce sont les autels de la mère cosmique, la pachamama, les arbres, les cascades, les rivières, les lagunes ont une voix qui a un caractère magique car ils sont jumelés à l'humanité. Ils conversent avec nous et nous pouvons aussi parler avec les plantes et les animaux. Aussi, la radio est un outil effectivement hautement révolutionnaire qui porte cette voix magique dans les coins les plus reculés. Si le paysan se reconnait dans cette voix qui est la sienne, c'est mille fois mieux que 
n'importe quelle autre solution, parce que cela lui fait sentir que c'est lui qui parle, il dit ses mots, il dit ce qu'il pense, il dénonce les injustices, ce qu'il lui manque de la part de l'État. La radio participe à la grande œuvre d'inclusion sociale, pour réunir ces gens et canaliser tous ces efforts pour construire une société plus juste, plus égalitaire, plus démocratique. La radio est ce qu'il y a de moins cher: on peut faire une radio avec moins de 2000 dollars, avec un émetteur et le matériel audio et porter la voix des enfants, des femmes, des anciens, ainsi que les contes, les chansons, les mythes. Et cela change absolument tout parce faire entendre sa propre voix à une société totalement marginalisée, opprimée, condamnée au silence sous toutes ses formes est ce qu'il peut être fait de plus révolutionnaire. La force acquise grâce à ces outils est irrésistible. Les gouvernements le savent bien. Il existe aujourd'hui un réseau de radios indigènes, de radios quechuas, de radios communautaires qui contrebalance la radio officielle de Lima, laquelle diffuse la voix de l'oppression, de la domination. Les petites communautés ont leur émetteur radio. Cela fait pas mal de temps que nous développons ces petites radios avec l'idée d'un réseau quechua entre le Pérou, la Bolivie et l'Équateur, pour relier toutes ces petites stations et faire circuler les informations, la musique, les chants, etc.

\section{JG-DT - Tu as également participé à des projets radiophoniques financés par la} BBC

LCB - Tout à fait. En 1994, la BBC a signé une convention avec l'UNICEF de New York, pour lancer une série d'émissions en quechua dans le cadre de campagnes de santé publique. J'ai eu l'occasion d'animer cette radio qui, bien sûr, essayait de sensibiliser les populations quechua du Pérou, mais aussi de Bolivie et d'Équateur, aux problèmes de santé qui affectent plus particulièrement les communautés andines vivant dans la pauvreté. Cela concernait la prévention des maladies infectieuses, les campagnes de vaccination et aussi l'alcoolisme très répandu chez les hommes. Mais cette radio diffusait également de la musique, des chansons des diverses régions, des reportages sur les traditions orales et initiatives locales. Ces émissions circulaient également sous forme de cassettes et ont eu beaucoup de succès. Depuis, nous avons également reçu le soutien d'une ONG qui travaille beaucoup en milieu rural, le CEPES (Centro Perunao de Estudios Sociales), notamment en 2009, quand il y a eu une vague de froid intense qui a beaucoup affecté la population de Puno et de l'Apurimac. Le CEPES, en concertation avec la FAO, a lancé une série de programmes radiophoniques pour prévenir et aider les gens. Les émissions ont été diffusées grâce à un réseau d'une quarantaine de petits émetteurs disséminés dans la campagne et pilotés par des animateurs quechuas. Nous avons organisé un séminaire de préparation avant de nous intéresser à la production et la diffusion à proprement dit. Le réseau touche environ 1,5 millions de locuteurs quechuas dans les régions rurales de Cusco, de l'Apurimac et de Puno.

\section{JG-DT - Comme souvent chez les peuples minorisés, l'exil rural vers les villes est} la façon d'échapper à la misère. Comment cela s'est-il passé au Pérou ?

LCB - La ville de Lima concentre la majeure partie de l'industrie, du commerce, de l'éducation, etc. Aujourd'hui, $85 \%$ des activités économiques du pays se trouvent à Lima. Dans les années 1940-50, il y a eu une grande vague d'immigration des régions andines, mais plus particulièrement de ce que l'on appelle la Manche Indienne (Ayacucho, Apurimac et Huancavelica), non seulement parce qu'elle a le plus grand nombre de locuteurs quechuas, mais également parce que c'est la zone la plus pauvre, au-dessous du seuil de pauvreté. C'est ce qui a provoqué cette vague d'immigration vers 
la capitale. Chez ceux qui ont quitté leur terre, il y a eu beaucoup de nostalgie. Aussi, autant pour se défendre et se protéger de l'hostilité et de l'insécurité rencontrées à Lima, les paysans se sont regroupés au sein d'une petite association, afin d'établir rapidement des liens avec d'autres institutions semblables dans leur propre province ou région d'origine, au point de fonder dans les années 1980 des fédérations d'associations régionales. Ceci avant de conjuguer leurs efforts, pas seulement pour chanter et danser, mais pour soutenir leurs communautés, par exemple pour défendre leurs ressources naturelles, réclamer la construction d'écoles, de dispensaires ou de routes. Et dans les années 1980-90, il y a eu une vague migratoire provoquée par le terrorisme, la violence politique de l'extrême-gauche maoïste. On est arrivé à un tel niveau de violence que, par exemple, selon les chiffres de la Commission pour la vérité, l'État a tué autant de personnes que les terroristes. En vingt ans, il y a eu 70000 morts, dont $74 \%$ de locuteurs quechuas. Comme le disait le ministre de l'intérieur : si, sur cent indigènes morts dans une communauté, il y avait deux terroristes (ceux-ci ne portaient jamais d'uniforme et se mêlaient à la population), alors les cent morts étaient justifiés ; c'était le prix à payer. La répression s'abattait de façon tellement aveugle que n'importe qui pouvait être tué, sans aucune justification. Cela a provoqué, non seulement une émigration des indigènes et des métis vers des villes comme Lima, Ica, Trujillo, Chimbote, mais aussi vers des villes de l'intérieur comme Cusco, Abancay, Arequipa, des petites villes de montagne. Ce qui est intéressant, c'est que Lima reproduit toutes les fêtes du Pérou profond, avec les danses, les chansons et les rituels religieux marqués par le syncrétisme, mêlant croyances catholiques et croyances indigènes comme la vierge et la pachamama. C'est ce que l'on peut voir régulièrement sur la place principale, près du palais présidentiel quand des milliers de personnes se réunissent à l'occasion de fêtes traditionnelles.

\section{JG-DT - En quoi ces contes ou chansons peuvent avoir une portée politique ?}

24 LCB - En 2015, grâce à une coopérative de l'Apurimac, un concours a été organisé et une jeune fille de 18 ans a écrit un conte en quechua, là où les règles indiquait, chose incroyable dans le pays de José María Arguedas, qu'il fallait rédiger en castillan. J'ai extrait le conte qu'elle a écrit, intitulé Rumipa Wipin (Les pleurs de la pierre), parce que la pierre pleure, parce que la nature est notre mère. Dans le conte, un enfant voit que la déforestation a détruit la nature et la pierre pleure parce le monde arrive à sa fin : « Tu as un cour de pierre, alors tu ne sens rien", mais dans le monde andin, les pierres sont unies aux gens, elles ont une âme, une voix. Il n'y a donc rien d'anormal qu'elles pleurent à cause de la destruction de la nature et de la déforestation. C'est une plaidoirie contre le réchauffement climatique global, contre les dommages causés par l'industrie et par les mines : $75 \%$ de ce territoire si pauvre de l'Apurimac est l'objet de concessions à des entreprises étrangères. Le gouvernement n'exige rien en retour pour ce qui est du respect de l'environnement.

Un autre conte venant d'Ayacucho, près de l'Apurimac, a pour titre Les petits soldats et dénonce l'incursion de soldats de l'armée dans une communauté indigène. Ils arrivent à 9 heures du soir dans le village et font sonner les cloches : à cette heure, tout le monde dort parce que dans les communautés rurales, les gens se lèvent à 3 heures du matin. Les gens ne savent pas ce qu'il se passe, car le jeu des cloches ne correspond à rien de connu: ce n'est pas l'appel de la messe, ou pour un enterrement, ou une alerte incendie. Les soldats frappent aux portes et crient « allez tous sur la place, celui qui refuse est un terroriste et sera fusillé ». C'était des soldats de l'armée qui prétendaient défendre 
les intérêts des gens de la ville contre les incursions terroristes. Alors que les gens étaient réunis sur la place, les soldats se sont rendus dans les maisons, ont pris des ponchos de bonne qualité, des vêtements, des radios et des magnétophones, une horloge et ont tout mis à sac. C'est un exemple de la manière la «plus douce » dont la répression s'exerce pour punir une communauté où parfois se cachent des hommes du Sentier lumineux. Pendant des années, de nombreux villageois ont dû organiser des comités de surveillance et vivre dans des collines et dans des grottes, abandonnant leurs cultures, leur bétail, pour fuir ces abus de l'armée. Ces contes s'inspirent du travail de José María Arguedas, un écrivain qui s'est beaucoup intéressé à la culture andine et a produit des écrits, des nouvelles où le réalisme l'emporte souvent sur la fiction. Voilà en quoi les chansons ou les contes, mais aussi la musique et la danse vont au-delà du divertissement, unissent les gens et participent à la reconnaissance de la culture quechua.

JG-DT - Tu parles beaucoup de José María Arguedas, écrivain et ethnologue péruvien. Il t'a beaucoup inspiré ?

LCB - Je l'ai connu en 1963. J'avais obtenu une bourse pour faire de la poésie, mais mon tuteur et conseiller ne me laissait pas écrire ce que je voulais. Il me disait de lire les symbolistes français comme Baudelaire. Je me suis plaint au directeur de l'institution qui me donnait la bourse qu'on ne me laissait pas écrire. Je me sentais comme mutilé, vaincu. Alors, ils m'ont mis en contact avec Arguedas. Sa femme était vice-ministre de l'éducation et directrice de la bibliothèque nationale. Il m'a dit de ne pas m'inquiéter et que le meilleur service que je pouvais rendre à la culture et à la poésie du Pérou était d'écrire toutes les chansons que je connaissais, de les traduire et de les publier. J'ai écrit sur des cahiers 1700 chansons. Malheureusement, ma maison a été inondée avec des pluies d'orage et tous mes documents ont été abimés et je n'ai pas réussi à les récupérer. J'ai réussi à publier certaines choses ; j'ai également conservé de nombreux enregistrements audio de chansons qui sont au département d'ethnologie de l'université catholique de Lima. Mais ce n'est pas facile de faire publier ce patrimoine culturel au Pérou. Seule la tradition orale permet de transmettre cette culture.

\section{BIBLIOGRAPHIE}

Arguedas (José María), Canto Kechwa, Lima, Horizonte, 1938.

Arguedas (José María), Ríos Izquierdo (Francisco), Mitos, leyendas y cuentos peruanos, Madrid, Editorial Siruela, 2009.

Guyot (Jacques) dir., Cultures de résistance. Langues et peuples minorisés, Paris, Presses des Mines, 2020.

Guyot (Jacques), Téphany (Danièle), Minorités et cultures de résistance, http://

jacquesguyotetdanieletephany.net/. 
Guyot (Jacques), « Les représentations médiatiques des minorités linguistiques comme enjeu socio-politique. Étude de cas dans les Andes péruviennes ", in Ballarini (Loïc), Delavaud (Gilles) ed., Nouveaux territoires médiatiques, Paris, Mare \& Martin, 2014, pp. 207-237.

Hoggart (Richard), La Culture du pauvre, Paris, Minuit, 1970. 